\title{
PERANCANGAN SISTEM INFORMASI AKADEMIK UNIVERSITAS MAHENDRADATA BERBASIS WEB DENGAN METODE WATERFALL
}

\author{
I Komang Pasek Sudiarsa \\ Program Studi Teknik Industri, Fakultas Teknik, Universitas Mahendradatta Bali \\ JI. Ken Arok No 12, Peguyangan Denpasar Utara, Bali 80115 \\ Email : kompassudiarsa@gmail.com
}

\begin{abstract}
Abstrak - Pengelolaan kegiatan-kegiatan akademik di Universitas Mahendradata masih dilakukan secara manual, dalam artian belum menggunakan sistem informasi yang terintegrasi, seperti dalam proses registrasi mahasiswa baru, penyusunan jadwal perkuliahan, pengisian KRS mahasiswa, pengelolaan presensi perkuliahan, dan pengelolaan nilai mahasiswa. Saat ini perubahan budaya telah ditandai dengan adanya pemanfaatan internet yang semakin pesat. Internet sebagai penyampai informasi keberadaannya kini sudah menjadi kebutuhan. Manfaat internet cukup besar dirasakan terutama dalam dunia bisnis, hiburan dan pendidikan. Sistem yang dirancang ini bertujuan untuk membantu proses-proses akademik di Universitas Mahendradata. Proses-proses akademik yang telah dianalisa dan diterapkan pada sistem yang dikembangkan ini adalah proses penyusunan jadwal, plotting dosen pengajar, cetak KRS, cetak presensi perkuliahan, input presensi, pengisian nilai, dan cetak KHS. Dan pihak Universitas dapat segera mengembangkan sistem yang baru agar dapat bekerja dengan maksimal. Perancangan sistem yang telah digunakan pada pengembangan sistem ini menggunakan metode SDLC, metode waterfall. Implementasi sistem menggunakan bahasa pemrograman PHP Codegniter dan database MySQL. Hasil penelitian ini berupa rancangan sistem akademik di Universitas Mahendradata. Sistem yang dikembangkan ini bertujuan untuk membantu proses-proses akademik yang terdapat di Universitas Mahendradata.
\end{abstract}

Kata Kunci : Sistem Informasi Akademik, Universitas Mahendradata, Metode Waterfall, Bahasa Pemrograman

\begin{abstract}
Management of academic activities at Mahendradata University is still using manually ways, which means that it has not used an integrated information system yet, for the example the process of registering new students, arranging lecture schedules, filling in student $K R S$, managing lecture attendance, and managing student grades. Nowadays cultural changes have been marked by the increasingly rapid use of the internet. The internet as an information resources for its existence has now become a necessity. The benefits of the internet are quite large, especially in the world of business, entertainment and education. This system is designed to assist academic processes at the University of Mahendradata. The academic processes that have been analyzed and applied in this developed system are the process of preparing schedules, plotting teaching lecturers, printing KRS, printing lecture attendance, presenting inputs, filling in grades, and printing KHS. And the University can immediately develop a new system in order to work optimally. System design that has been used in developing this system uses the SDLC method, the waterfall method. The implementation of the system uses the PHP programming language Codegniter and MySQL database. The results of this study are in the form of an academic system design at the University of Mahendradata. This developed system is aim to assist the academic processes at the University of Mahendradata
\end{abstract}

Keyword : Academic Information System, Mahendradata University, Waterfall Method, Programing Language 


\section{PENDAHULUAN}

Perkembangan teknologi informasi yang cepat menuntut penyampaian informasi yang cepat dan akurat. Universitas Mahendradata sebagai salah satu Instansi pendidikan diharapkan dalam penyampaian informasi khususnya dibidang akademik dapat lebih efektif dan efisien. Mutu informasi sangat mempengaruhi kinerja dan hasil kerja dari pengelola pendidikan dan bagi peserta didik.

Saat ini system informasi berbasis web merupakan salah satu sumber informasi yang banyak digunakan. Aplikasi berbasis web dibuat dengan tujuan agar pemakai dapat berinteraksi dengan penyedia informasi dengan mudah dan cepat, yaitu melalui dunia internet. Aplikasi web juga mampu memberikan informasi yang dinamis dengan melakukan koneksi database secara langsung.

Manfaat internet cukup besar dirasakan terutama dalam dunia bisnis, hiburan dan pendidikan.Segala sesuatu informasi bias kita dapatkan dimanapun dan kapanpun juga saat itu. Perkembangan teknologi yang ada mendukung juga perkembangan dari system informasi yang berkembang di masyarakat, seperti perkembangan Sistem Informasi Akademik.

Pengelolaan kegiatan akademik masih dilakukan secara manual, Bidang Akademik menemui berbagai kendala dalam prosesproses tersebut terutama yang berkaitan dengan sumber daya dan waktu yang diperlukan, seiring dengan makin besarnya jumlah mahasiswa yang dikelola. Begitu pula dengan belum diterapkannya sistem yang terintegrasi, koordinasi antara satu bagian dengan bagian lain, dalam Bidang Akademik belum maksimal. Berdasarkan uraian diatas diperlukan suatu solusi untuk memecahkan permasalahan tersebut, dimana dalam hal ini dapat diterapkan suatu sistem informasi yang terkomputerisasi untuk memudahkan Bagian Akademik Universitas Mahendradata menjalankan kegiatankegiatannya.

Sistem informasi yang terintegrasi, seperti dalam proses registrasi mahasiswa baru, penyusunan jadwal perkuliahan, pengisian KRS mahasiswa, pengelolaan presensi perkuliahan, dan pengelolaan nilai mahasiswa dijadikan ke dalam satu kesatuan system informasi.
Mengingat sekarang perkembangan teknologi informasi berbasis web sangat pesat dan akses internet di Indonesia cukup berkembang pesat, maka penulis mengajukan usulan penelitian Perancangan Sistem Informasi Akademik Universitas Mahendradata Berbasis Web, dengan harapan Sistem Akademik Universitas Mahendradata ini bias di akses kapanpun dan di manapun asal ada akses internet. Dengan dilakukannya perancangan sistem informasi akademik ini diharapkan semua kegiatan atau proses akademik yang terdapat pada Universitas Mahendradata dapat diterjemahkan kedalam bahasa pemrograman atau dikomputerisasi dengan baik untuk diimplementasikan, sehingga dapat mengatasi berbagai kendala yang dihadapi.

Perancangan Sistem Informasi Akademik ini menggunakan diagram UML yang terdiri dari Use case diagram, activity diagram, sequence diagram, dan class diagram. Proses akademik yang diterapkan pada rancangan sistem yang diusulkan ini adalah penyusunan jadwal kuliah, plotting dosen pengajar, pencetakan KRS, presensi mahasiswa, pengisian nilai, serta pencetakan KHS mahasiswa. Pengkodean program menggunakan bahasa pemrograman PHP dengan framework Codeigniter dan database MySQL.

\section{METODE PENELITIAN}

Bagian ini berisi tentang metode penelitian dan cara pendekatan yang digunakan pada penelitian, serta sistematika penelitian yang secara umum dijelaskan sebagai berikut.

\section{A. Metode Pengembangan Sistem}

Metode pengembangan system menggunakan metode System Devlopmen Life Cycle (SDLC) dengan model Waterfall Penggunaan SDLC yang memadai akan menghasilkan sistem informasi yang berkualitas. Penggunaan SDLC akan lebih optimal jika dilengkapi dengan berbagai teknik pengembangan sistem. Siklus hidup pengembangan Sistem atau SDLC adalah metodologi untuk merancang, membangun, dan memelihara informasi dan proses sistem. Terdapat banyak model SDLC, salah satunya adalah model Waterfall yang terdiri dari lima tahap untuk secara berurutan diselesaikan dalam rangka untuk mengembangkan solusi perangkat lunak 
(Bassil, 2012). Waterfall adalah model pengembangan sistem yang menjadi dasar atau awal untuk model pengembangan sistem lainnya (Khurana, 2012)

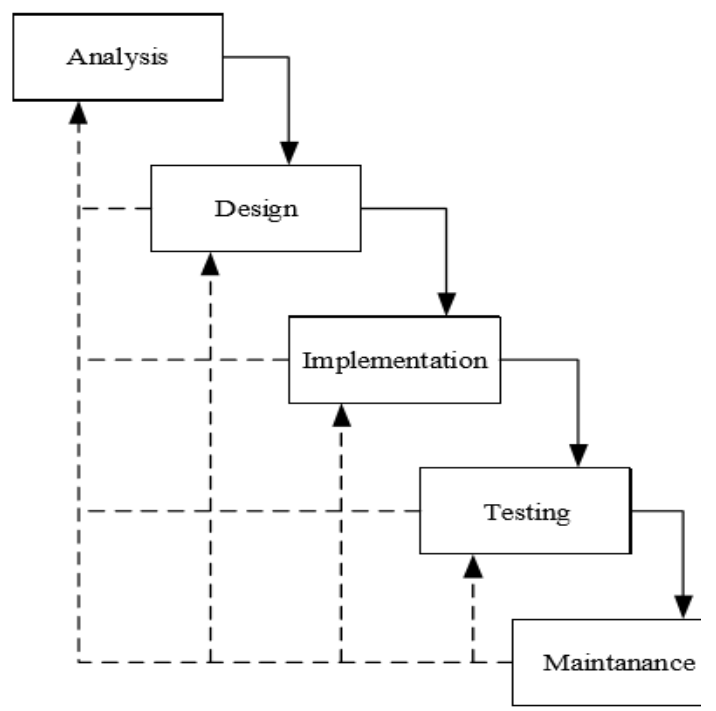

Gambar 1. Metode Waterfall

\section{Tahapan Metode Waterfall}

\section{Analisis Kebutuhan}

$\begin{array}{llr}\text { Layanan sistem, kendala, dan tujuan } \\ \text { ditetapkan oleh hasil } & \text { konsultasi } \\ \text { denganpengguna yang } & \text { kemudian } \\ \text { didefinisikan secara rinci dan } & \text { berfungsi } \\ \text { sebagaispesifikasi sistem. } & \end{array}$

\section{Desain sistem}

Tahapan perancangan sistem mengalokasikan kebutuhan-kebutuhan sistem baik perangkat keras maupun perangkat lunak dengan membentuk arsitektur sistem secara keseluruhan. Perancanganperangkat lunak melibatkan identifikasi dan penggambaran abstraksi sistem dasar perangkat lunak dan hubungannya.

\section{Implementasi}

Pada tahap ini, perancangan
perangkat lunak direalisasikan
sebagaiserangkaian program atau unit
program.Pengujianmelibatkanverifikasibah
wasetiap unit memenuhi spesifikasinya.

\section{Testing atau Pengujian Sistem}

Unit-unit individu program atau program digabung dan diuji sebagai sebuah sistem lengkap untuk memastikan apakah sesuai dengan kebutuhan perangkatlunak atau tidak.Setelah pengujian, perangkat lunak dapat dikirimkan ke penguna.

\section{Maintenance atau Pemeliharaan}

Biasanya (walaupun tidak selalu), tahapan ini merupakan tahapan yang paling panjang. Sistem dipasang dan digunakan secara nyata. Maintenance melibatkan pembetulan kesalahan yang tidak ditemukan pada tahapan tahapan sebelumnya, meningkatkan implementasi dari unit sistem, dan meningkatkan layanan sistem sebagai kebutuhan baru.

\section{B. Metode pengujian Sistem}

Menurut R. A. Sukamto and M. Shalahuddin, black box testing adalah menguji perangkat lunak dari segi spesifikasi fungsional tanpa menguji desain dan kode program. Pengujian dimaksudkan untuk mengetahui apakah fungsi-fungsi, masukan, dan keluaran dari perangkat lunak sesuai dengan spesifikasi yang dibutuhkan. Pengujian kotak hitam dilakukan dengan membuat kasus uji yang bersifat mencoba semua fungsi dengan memakai perangkat lunak apakah sesuai 25 dengan spesifikasi yang dibutuhkan. Kasus uji yang dibuat untuk melakukan pengujian black box testing harus dibuat dengan kasus benar dan kasus salah( $T$. Wahyunningrum and $D$. Januarit).

\section{HASIL DAN PEMBAHASAN}

Pengembangan sistem dalam penelitian ini menggunakan metode Rekayasa Sistem Berbasis Komputer berdasarkan prinsip- prinsip rekayasa perangkat lunak (Software Engineering) melalui tahapan pengembangan berdasarkan daur hidup. SDLC (System Development Life Cycle). SDLC terdiri dari perencanaan, analisa sistem, perancangan sistem, implementasi sistem, operasidan perawatan sistem. Adapun tahapannya sebagai berikut:

\section{Perencanaan (Planing)}

a. Metode Pengumpulan data Metode pengumpulan data yang digunakan dalam penelitian ini adalah:

1) Pengamatan Langsung (Observasi) Peneliti mengamati langsung pada obyek yang akan diteliti, dalam hal ini proses input jadwal kuliah oleh penanggung jawab, 
pengisian Kartu Rencana Studi dan cetak oleh mahasiswa, pengisian nilai oleh dosen serta proses administrasi pembayarannya.

2) Wawancara Peneliti mengumpulkan data dengan melakukan wawancara pada orang yang berkompeten pada Perguruan Tinggi dimana obyek penelitian itu dilakukan yaitu dengan siswa, karyawan, staff pengajar dan pimpinan untuk mendapatkan data dan informasiyang akurat dan dapat dipertanggung jawabkan dengan baik.

3) Studi Pustaka (Library Research Method) Yaitu metode pengumpulan data dengan jalan membaca bukuatau literature, jurnal penelitian, artikel dari internet serta sumber data lainnya yang berhubungan dengan masalah yang diteliti. Tahapan perencanaan terdapat point-point yang harus dijalankan, yaitu:

- Mengenali Masalah

- Mengidentifikasi Masalah

- Tujuan untuk Pemecahan Masalah

- Mengidentifikasi hambatanhambatan yang sering muncul

- Melakukan Pembelajaran Teknologi

\section{Analisis Sistem (Sistem Analys)}

Tahapan analisis memiliki langkah sebagai berikut:

a. Menganalisis Data Data yang dibutuhkan dalam sistem baru ini adalah:

1) Data Inputan Data inputan merupakan data master meliputi: identitas universitas, data fakultas, data program studi, data kelas, data kurikulum, data mahasiswa, data dosen, data ruangan.

2) Data Proses/transaksi Data transaksi merupakan data hasil dari proses relasi data inputan yang meliputi: data KRS, data KHS, data pembayaran.

3) Data Outputan Data keluaran yang dihasilkan adalah cetak kartu KRS dan KHS, kartu ujian serta presensi perkuliahan. b. Menentukan Kebutuhan Informasi

Untuk menghasilkan sistem yang baik maka dibutuhkan beberapa komponen pembentuk sistem diantaranya:

1) Kebutuhan Hardware Hardware atau perangkat keras yang dibutuhkan dalam membangun sistem akademik dan keuangan spesifikasi yang utama adalah mengenai kapasitas dan kinerja perangkat Memori, Prosesor.

2) Kebutuhan Software Software atau perangkat lunak yang dibutuhkan dalam membangun analisa dan perancangan sistem informasi akademik dan keuangan.

3) Kebutuhan User/Brainware Dalam sistem akademik ini membutuhkan pelaku utama atau user bisnis sistem 3(tiga) yaitu mahasiswa, Dosen dan pengelola program studi/admin.

\section{c. Menentukan Performance Sistem}

Untuk menghasilkan performance yang baik dibutuhkan desain sistem yang detail. Rincian fungsional sistem baru dapat digambarkan dengan suatu diagram yang berorientasikan objek. Hasil desain akan diimplementasikan dalam bentuk aplikasi online. Untuk menghasilkan performance yang baik dari hasil analisis dibutuhkan desain sistem yang detail. Rincian fungsional sistem baru dapat digambarkan dengan suatu diagram yang berorientasikan objek. Dalam hal ini desain sistem baru akan digambarkan dalam model UML (Unified Modelling Language). Sistem baru ini akan digambarkan dalam beberapa diagram, yaitu:

\section{Use Case Diagram}

Use Case Diagram menggambarkan apa saja yang dapat dilakukan oleh sistem. Sistem Informasi Akademik ini secara garis besar dapat melakukan Penyusunan jadwal kuliah, Plotting dosen pengajar, Pencetakan KRS, Presensi mahasiswa, Pengisian nilai, dan Pencetakan KHS mahasiswa. Pada use case ini terdapat 3 actor, yaitu Staff BAAK (Biro Administrasi Akademik)/admin, Dosen dan Mahasiswa 


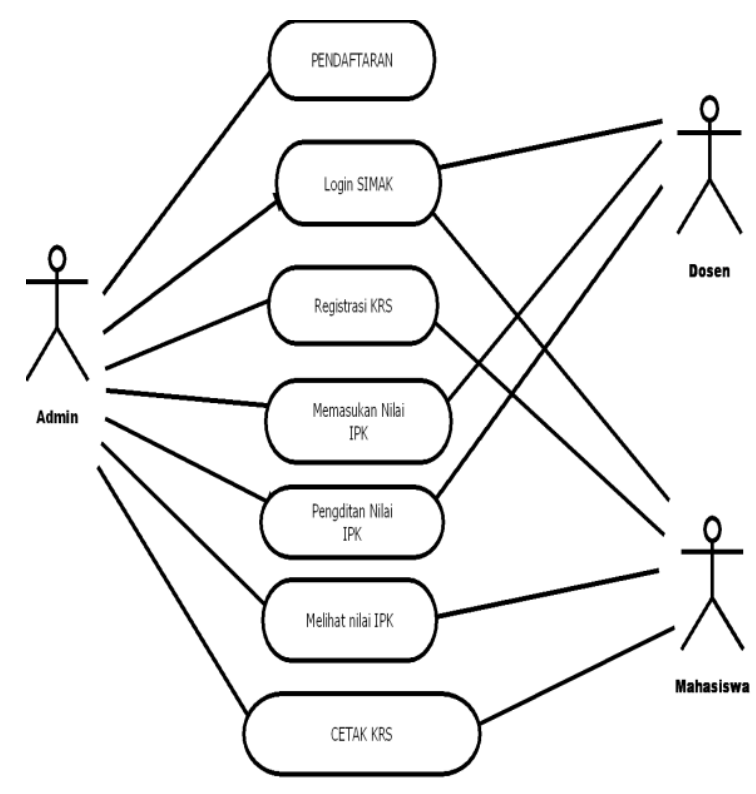

Gambar 2. Use Case Diagram

Dalam sistem pengembangan ini terdapat 3 aktor yang memiliki peranan penting dalam proses akademik yaitu mahasiswa, dosen, dan admin simak. Integrasi data dari masing - masing aktor saling mempengaruhi agar terjalin konsintensi dan keakuratan data. Sistem diawali dari mahasiswa diverifikasi dan di validasi hak akses dan pengontrolan sistem oleh admin SIMAK, sedangkan dosen berperan dalam pengelolaan nilai mahasiswa.

\section{d. Sequence Diagram}

SIMAK untuk mahasiswa terdapat 1 mahasiswa dan 4 objek, form login, database, dan halaman utama. Pertamatama mahasiswa akan mengakses SIMAK. Lalu pada form login, mahasiswa akan memasukkan username dan password. Setelah itu username dan password tersebut di cek pada database. Jika salah akan diberikan pesan kesalahan, sedangkan jika benar akan di tampilkan halaman utama. Pada halaman utama, mahasiswa melihat daftar nilai matakuliah.

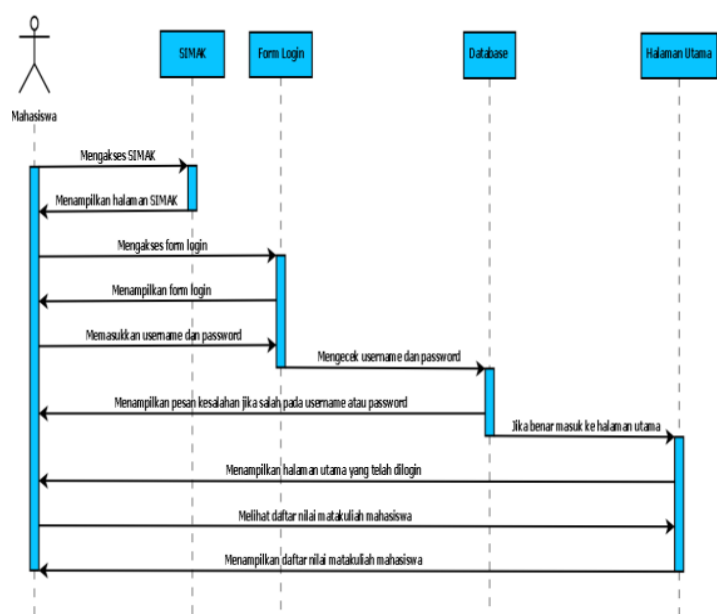

Gambar 3. Sequence Diagram

\section{Implementasi Sistem}

Sistem informasi akademik ini dikembangkan dengan menggunakan bahasa pemrograman PHP dengan Framework Codeigniter dan database Mysql. Dimana data yang digunakan diperoleh langsung dari Universitas Mahendradata

\section{Halaman Login SIMAK}

Saat Pertama kali akan mengakses aplikasi SIMAK, maka user akan dihadapkan dengan halaman login awal. User harus melakukan login sesuai username dan password yang di milikinya

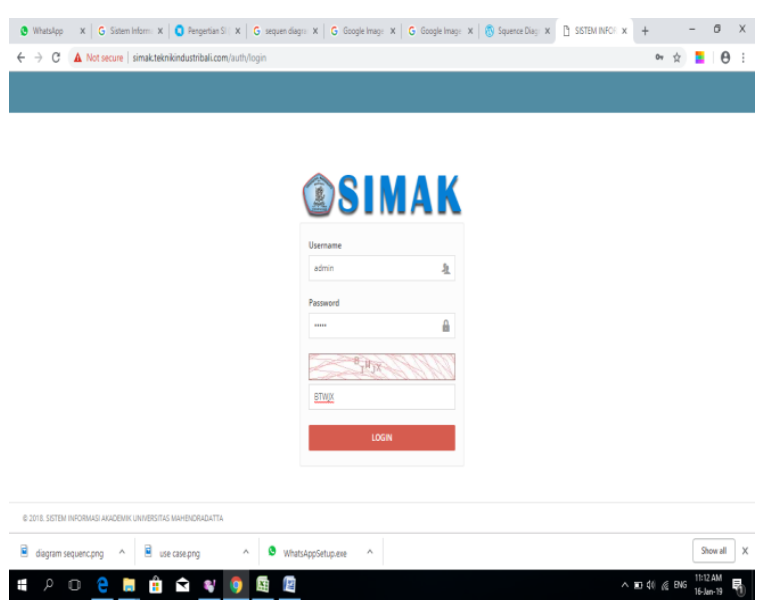

Gambar 4. Halaman Login

\section{Halaman Utama}

Jika login benar, maka akan masuk ke halaman utama dengan tampilan yang sama namum menu berbeda untuk setiap User 


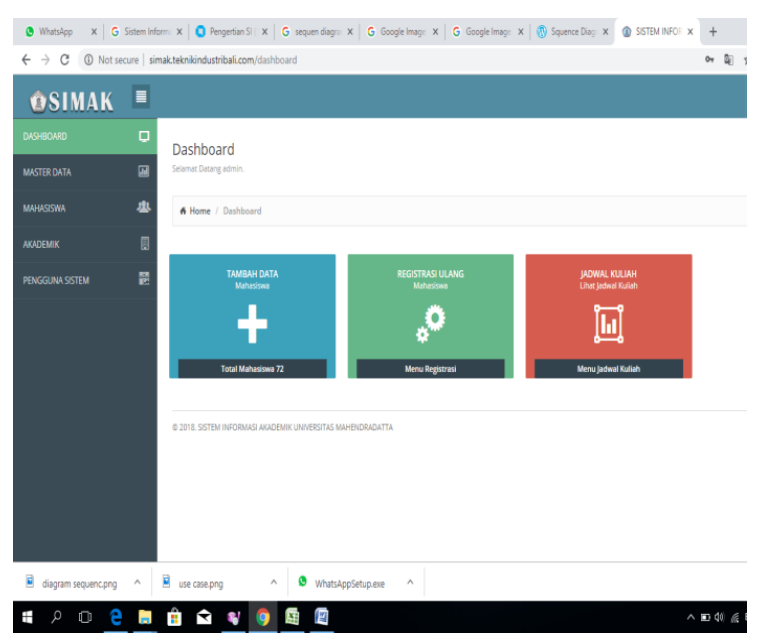

Gambar 5. Halaman Utama/Main Page

\section{Halaman Dosen.}

Halaman ini untuk melihat data dosen yang ada di Universitas Mahendradata. Yang bisa masuk kehalaman ini adalah admin dan dan user yang diberikan akses nantinya.

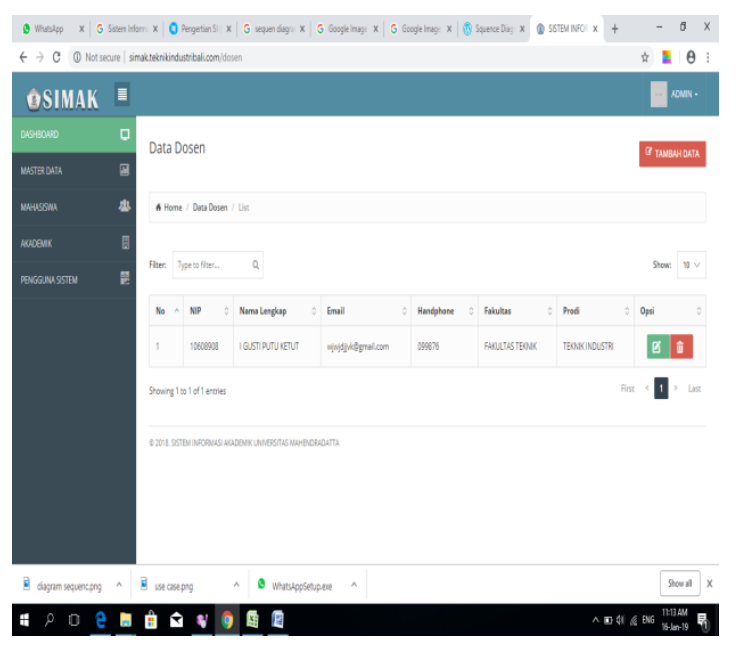

Gambar 6. Halaman Data Dosen

\section{Tampilan untuk pengambilan KRS}

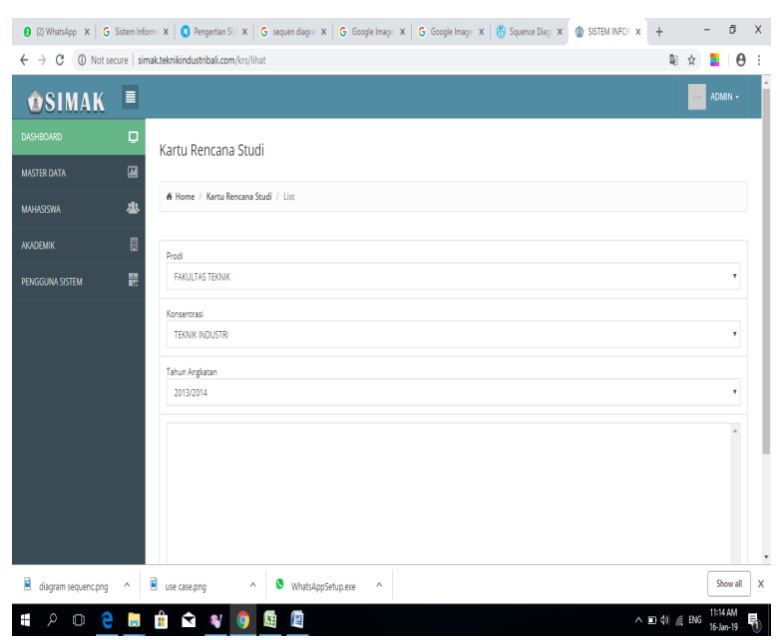

Gambar 7. Halaman KRS

\section{Tampilan Manajemen User}

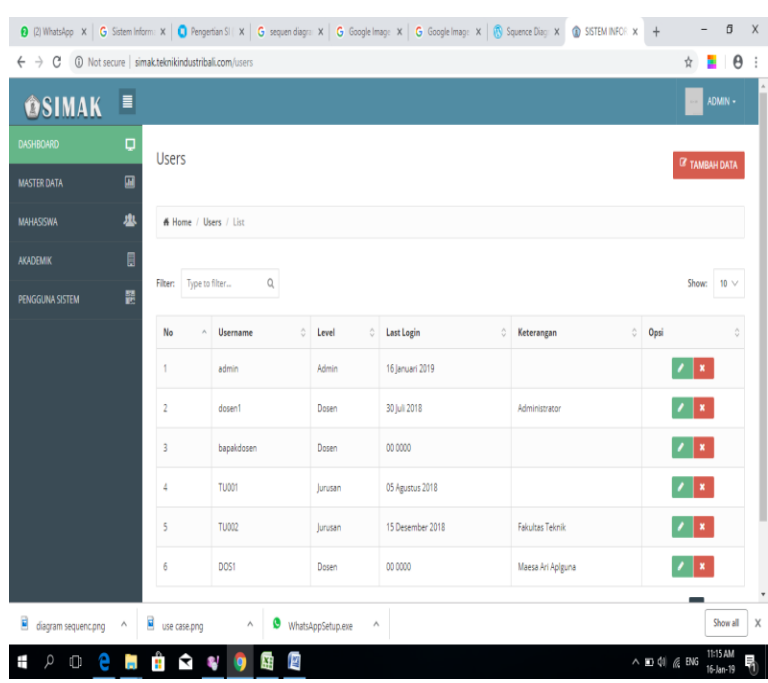

Gambar 8. Halaman Manajemen User

\section{KESIMPULAN DAN SARAN}

\section{Kesimpulan}

Sistem Informasi Akademik pada Universitas Mahendradata dirancangan menggunakan UML diagram, serta pengkodean program dengan bahasa PHP framework Codeigniter dan database Mysql. Sistem yang dirancang ini bertujuan untuk membantu proses-proses akademik di Universitas Mahendradata. Prosesproses akademik yang telah dianalisa dan diterapkan pada sistem yang dikembangkan ini adalah proses penyusunan jadwal, plotting dosen pengajar, cetak KRS, cetak presensi perkuliahan, input presensi, pengisian nilai, dan cetak KHS. Perancangan sistem yang telah digunakan pada pengembangan 
sistem ini menggunakan metode SDLC, metode waterfall.

\section{Saran}

Pada penelitian selanjutnya agar dicoba untuk mengembangkan perancangan sistem yang lebih luas lagi sehingga mampu mendukung lebih banyak lagi proses-proses akademik yang ada di Universitas Mahendradata. Selain itu pada penelitian selanjutnya agar dicoba untuk menerapkan pemrograman berbasis android sehingga bersifat lebih flexible dan dinamis dan dapat diakses disegala platform yang ada..

\section{Daftar Pustaka}

Al Fatta, H. (2007). Analisis \& Perancangan Sistem Informasi. Yogyakarta: Andi offset

Bassil Youssef., 2012,A Simulation Model For The Waterfall Software Development Life, International journal of Engineering \& Technology (iJET).

Fatta, Al Hanif. 2007. Analisis \& Perancangan Sistem Informasi, Yogyakarta : Penerbit ANDI

Jogianto. 2005. Analisis dan Desain Sistem Informasi. Yogyakarta : Penerbit ANDI

Khurana G, Gupta G, Sachin, 2012, Study \& Comparisonof Software Development Life Cycle Models. iJREAS.

Nugroho A. 2011. Perancangan Dan Implementasi Sistem Basis Data, Yogyakarta : Penerbit ANDI

R. A. Sukamto and M. Shalahuddin, Modul Pembelajaran Rekayasa Perangkat Lunak (Terstruktur dan Berorientasi Objek). Bandung: Modula, 2011.

Setiawan A, Yulia, Bangun Y. Pembuatan Aplikasi Sistem Informasi Akademik Di Sekolah Tinggi Thelogia Semara

Sommerville I., 2010, Software Engineering, 9th ed, Addison Wesley.

T. Wahyunningrum and D. Januarita, "Implementasi dan Pengujian Web E-commerce untuk Produk Unggulan Desa," J. Komput. Terap., vol. 1, no. 1, pp. 57 